\title{
Nonsurgical endodontic treatment of a large periradicular lesion
}

\author{
Fatma Kanmaz, Demet Altunbaş, Recai Zan, Kerem Engin Akpınar \\ Department of Endodontics, Cumhuriyet University Faculty of Dentistry, Sivas, Turkey
}

\begin{abstract}
In Endodontic, one of the most crucial problem that can result in the loss of teeth is periapical lesion. In the development of periapical lesion in periapical tissues, not only the presence of infected pulp but also the toxins, metabolic products, chemical agents, mechanical irritations, foreign substances, trauma and host defense of existing microorganisms also play a role. Radiographic findings, clinical oral examination and differential diagnosis are used in the diagnosis of periapical lesion. Even though endodontic treatment option combined with apical surgery could be an option for treatments of large periapical lesions, conventional root canal treatment should be the first choice that combined with long-term follow-up after treatment. The aim of this case report is to present a complete clinical and radiological healing of teeth relation with a large cyst-like periradicular lesion treated only with root canal treatment and without the need for a surgical treatment.
\end{abstract}

Keywords: Healing; large periapical lesion; non-surgical endodontic treatment.

E ndodontic failures can be attributable to inadequacies in shaping, cleaning and obturation, iatrogenic events, or re-infection of the root canal system when the coronal seal is lost after completion of root canal treatment. ${ }^{[1]}$ Moreover, the major reason of periradicular lesions associated with infected pulpal tissue are caused by pulpal inflammation and/or degeneration through deep caries, trauma, or by a combination of these. Any opening from the root canal system (RCS) to the periodontal ligament space should be thought of as a portal of exit through which potential endodontic breakdown products may pass. Consequently, the microbial aggregation or its by-products can infiltrate into periradicular tissues and stimulate the host defense system, resulting in periapical/ periradicular tissue destruction and results in various types of lesions. ${ }^{[2]}$ Periapical lesions classified into 5 main groups: Acute apical periodontitis, chronic apical periodontitis, condensing osteitis, acute apical abscess and chronic apical abscess. ${ }^{[3]}$ The general consensus is that bacterial reduction or elimination from the RCS by effective biomechanical preparation will lead to more successful outcomes. ${ }^{[4]}$ Investigators have shown that large periradicular lesion may respond positively to nonsurgical endodontic treatment. ${ }^{[5]}$ All inflammatory periapical lesions should be initially treated with conservative nonsurgical procedures. ${ }^{[6]}$ Because, endodontic treatment can approach $100 \%$ success discounting teeth that are nonrestorable, have hopeless periodontal disease. The goals of nonsurgical retreatment are to remove materials from the root canal space and if present, address deficiencies or repair defects that

Correspondence: Dr. Recai Zan. Cumhuriyet Üniversitesi, Diş Hekimliği Fakültesi,

Endodonti Anabilim Dalı, Sivas, Turkey.

Tel: +90 346 - 2191010 / 2764 e-mail: drrecaizan@hotmail.com

Submitted: January 20, 2017 Accepted: February 02, 2017

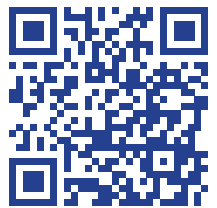




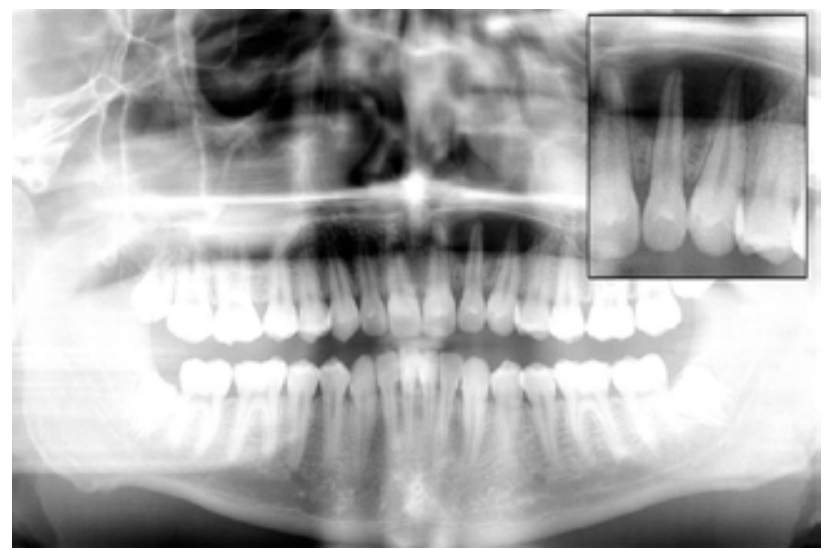

Fig. 1. The initial diagnostic panoramic and periapical radiography of the patient.

are pathologic or iatrogenic in origin. Nonsurgical endodontic retreatment procedures have enormous potential for success endodontic treatments. ${ }^{[7]}$

\section{Case report}

A 21-year-old male patient was referred to our clinic with severe pain on the left maxillary anterior region. The patient gave a history of trauma due to a traffic accident two years ago. Intraoral examination was determined a swelling in the vestibule mucosa, teeth mobility and sensitivity on percussion. Teeth 22 and 23 failed to respond to thermal and electric pulp testing; the adjacent teeth responded within normal limits. A periapical radiograph revealed a large radiolucent lesion approximately $18-19 \mathrm{~mm}$ in diameter apparently involving the apices of teeth 22 and 23 (Fig. 1). Following access cavity preparation, there was drainage of yellow straw-coloured fluid was aspirated from teeth 22,23 . The apical foramen was gauged using hand $\mathrm{K}$ - files, and the apical width was found to be equivalent to a size \#15 K- file. The apical foramen was widened to a size \#40 K- file and $\mathrm{H}$-type hand files under irrigation with $2.5 \% \mathrm{NaOCl}$ irrigation. The root canals were irrigated with $5.25 \% \mathrm{NaOCl}, 17 \%$ EDTA, normal saline and $2 \%$ chlorhexidine respectively for final irrigation. At the next appointment after 3 days, the patient was asymptomatic with no evidence of swelling in the labial vestibule but the exudate flow in the root canals was continuing. The same procedure of aspiration through the root canal space of tooth until the exudate flow is completely done. Then, calcium hydroxide dressing was applied once per week by three weeks. The canal was irrigated, dried and temporized. Three months has elapsed from the start of treatment. The root canals were obturated with cold lateral technique using AH Plus (Dentsply De Trey $\mathrm{GmbH}$, Konstanz, Germany) sealer and gutta-percha, and the access cavity was restored with composite resin (Fig. 2a). 2 months after root canals have been filled, the patient was still asymptomatic and a periapical radiograph revealed a decrease in the size of the radiolucency to approximately 9-10 mm in diameter (Fig. 2b). The patient was asymptomatic. A periapical radiograph revealed almost complete healing of the periapical lesion of canine tooth after 15 months. Furthermore, even though lateral tooth has shown a nice improvement, its healing was continuing (Fig. 2c).

\section{Discussion}

In large periapical lesions, there is a strong consensus on treatment with traditional root canal treatment or apical
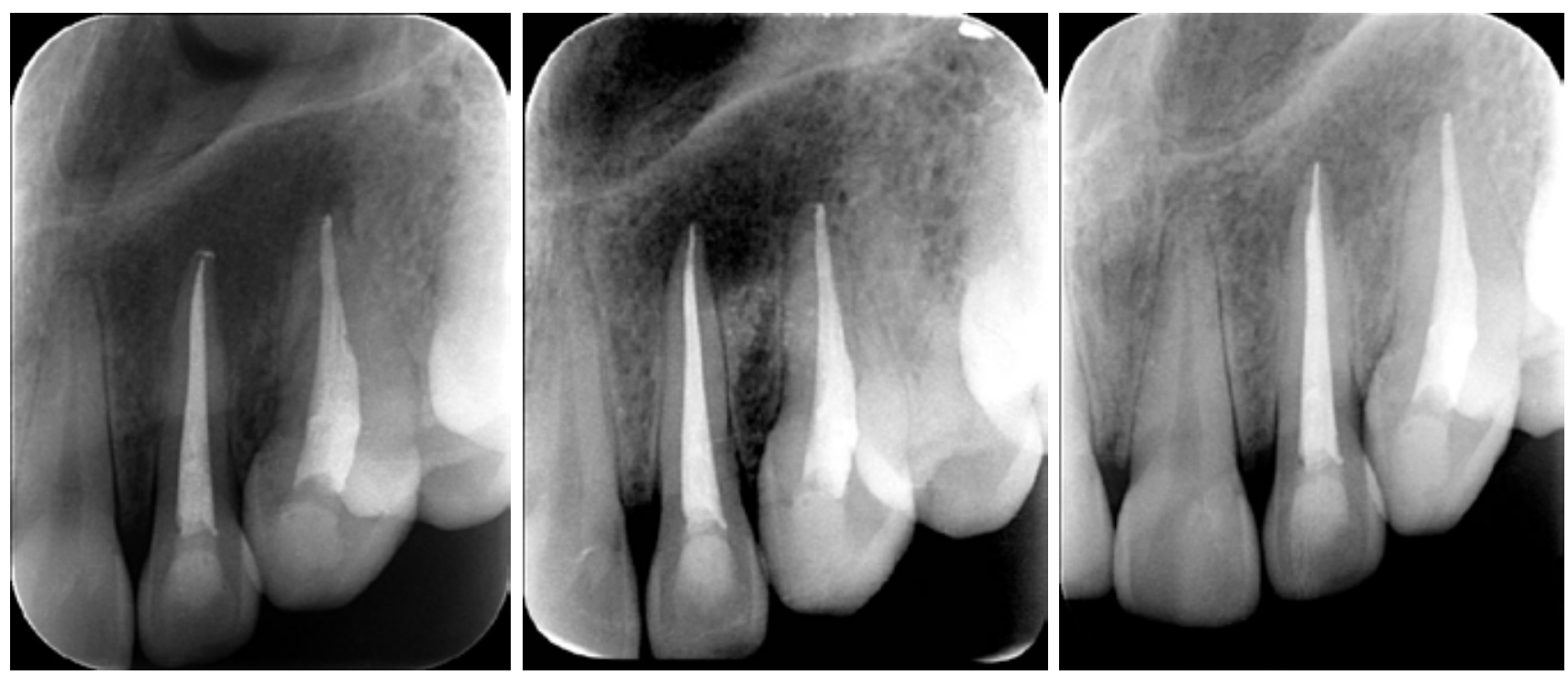

Fig. 2. (a) The radiography of root canal filling that performed after 3 months. (b) The radiographic image of root canals and surrounding periapical tissues 2 months after root canal filling. (c) The radiographic image of the healing of the periapical tissue at the end of 15 months follow-up. 
resection, but in many studies apical lesions of up to 20 $\mathrm{mm}$ have been reported to improve with conventional root canal treatment. ${ }^{[8]}$ Surgical treatment of cystic lesions has the disadvantages such as reducing bone support, destroying the inner blood vessels and nerves that feed the teeth adjacent to the surgical site, damaging of mental foramen, lower alveolar nerve branch and/or anatomical structures such as artery, nasal cavity, maxillary sinus, the formation of anatomical defects, postoperative pain, surgery in terms of cooperative was unable to pediatric patients. ${ }^{[9]}$ Because of these disadvantages, we prefer nonsurgical endodontic treatment as the treatment procedure in the cases presented. As mentioned in previous studies, in the cases of periradicular radiolucent lesions, sufficient biomechanical cleaning of the root canal system is the most critical factor for healing. It has been demonstrated that in these cases, nonsurgical root canal therapy should be the first line of treatment ${ }^{[10]}$ and approximately $74 \%$ of 42 endodontically treated teeth in a study showed bony healing within their large periradicular lesions. ${ }^{[11]}$ Nonsurgical treatment of the majority of root canals will result in complete repair of the largest periradicular lesions, including the cyst and in some cases the true cyst. ${ }^{[12]}$ Moreover, this patient was a young healthy subject and these factors will contribute to successful radiographical and clinical healing; previous studies have showed that the patient's general health may have an influence on the healing process in periradicular lesions. ${ }^{[10]}$ Furthermore, before the endodontic treatment of large periapical lesions is complete, the application of $\mathrm{Ca}(\mathrm{OH})_{2}$ as a medicament for certain periods of time has a positive effect on success to avoide the symptoms and to under control the periradicular infection. ${ }^{[13]}$ Calcium hydroxide is the preferred intracanal medicament due to its beneficial effects because, calcium hydroxide nowadays is widely used as an intracanal endodontic material, due to its high alkalinity ${ }^{[14]}$ tissue dissolving effect, causes induction of repair by hard tissue formation and bactericidal effect. ${ }^{[15]}$ During the root canal shaping, a 5.25\% sodium hypochlorite solution was used followed by a calcium hydroxide-based root canal dressing. Usage of calcium hydroxide paste was advocated for rapid and successful treatment of sinus tracts associated with necrotic teeth. ${ }^{[16]}$ The root canal dressing was applied once per week by three weeks and completed after 3 months. In this way, high alkalinity and calcium ion availability were obtained and maintained. Significant bone formation was seen at the periapical region on periodic check up visits. Thus nonsurgical healing of the multiple periapical lesions provided favourable clinical and radiographic response. Here, conventional endodontic therapy in combination with calcium hydroxide as an intracanal medicament contributed effectively in healing of periapical lesions. But, it would be necessary to observe and monitor the periapical lesions over a period of time following the nonsurgical approach. Caliskan reported that around $70 \%$ of cases with periapical lesions were healed within 2 years. ${ }^{[1]}$ However, some authors have also informed that many cases with periapical lesions the healing of the lesion is occured in first 1-12 months. ${ }^{[17]}$ In these presented cases, we have seen that complete healing was provided as a result of 15 months observation for lateral. In radiographic examination, change of densities in the lesion, reconstruction of the trabecular structure, lamina dura formation in apical region, asymptomatic formation of teeth in clinical examination and healthy appearance of soft tissues ${ }^{[18]}$ indicate us that the treatment has been successful.

\section{Conclusions}

This case report confirms that the size of a periapical lesion is not a major determining factor in the decision to perform conventional root canal treatment or surgical removal of the lesion. Large periapical lesions can heal after successful endodontic treatment without surgical intervention. The number of dressings with $\mathrm{Ca}(\mathrm{OH})_{2}$ until the completion of treatment, clinical examination between sessions and periodic radiographic follow-up is very important in terms of heal the periapical lesion. This case showed healing after 6 and 15 months clinical and radiographic follow-up.

Conflict of interest: None declared.

\section{References}

1. West JD. The relation between the three-dimensional endodontic seal and endodontic failure, Master Thesis, Boston University 1975.

2. Maalouf EM, Gutmann JL. Biological perspectives on the non-surgical endodontic management of periradicularpathosis. Int Endod J 1994;27:154-62. Crossre

3. Torabinejad M, Walton RE. Principles and Practice of Endodontics. 2nd ed. Philadelphia: W. B. Saunders Co., 1996. p. 29-51.

4. Broon NJ, Bortoluzzi EA, Bramante CM. Repair of large periapical radiolucent lesions of endodontic origin without surgical treatment. Aust Endod J 2007;33:36-41. Crossre

5. Ozan U, Er K. Endodontic treatment of a large cyst-like periradicular lesion using a combination of antibiotic drugs: a case report. J Endod 2005;31:898-900. Crossre.

6. Lin LM, Huang GT, Rosenberg PA. Proliferation of epithelial cell rests, formation of apical cysts, and regression of apical cysts after periapical wound healing. J Endod 2007;33:908-16. Crossret

7. Schilder H. Filling root canals in three dimensions. Dent Clin North Am 1967. p. 723-44. 
8. Mirkoviç S, Tadiç A, Durdeviç Mirkoviç T, Levakov A. Comparative analysis of accuracy of diagnosis of chronic periapical lesions made by clinical and histopatological examination. Med Pregl 2012;65:277-80. Crossree

9. Shah N. Nonsurgical management of periapical lesions: a prospective study. Oral Surg Oral Med Oral Pathol 1988;66:365-71. Crossse

10. Broon NJ, Bortoluzzi EA, Bramante CM. Repair of large periapical radiolucent lesions of endodontic origin without surgical treatment. Aust Endod J 2007;33:36-41. Crosser

11. Calişkan MK. Prognosis of large cyst-like periapical lesions following nonsurgical root canal treatment: a clinical review. Int Endod J 2004;37:408-16.

12. Maalouf EM, Gutmann JL. Biological perspectives on the non-surgical endodontic management of periradicularpathosis. Int Endod J 1994;27:154-62. Crosste

13. Paredes-Vieyra J, Enriquez FJ. Success Rate of Single- versus Two-visit Root Canal Treatment of Teeth with Apical
Periodontitis: A Randomized Controlled Trial. J Endod 2012;38:1164-9. Crossser

14. Tronstad L, Andreasen JO, Hasselgren G, Kristerson L, Riis I. $\mathrm{pH}$ changes in dental tissue after root canal filling with calcium hydroxide. J Endod 1981;7:17-21. Crossre

15. Siqueira JF, Lopes HP. Mechanisms of antibacterial activity of calcium hydroxide: a critical review. Int Endod J 1999;32:361-69. Crossret

16. Pasternak-Junior B, Teixeira CS, Silva-Sousa YT, SousaNeto MD. Diagnosis and treatment of odontogenic cutaneous sinus tracts of endodontic origin: Three case studies. Int Endod J 2009;42:271-6. Crossse-

17. Öztan MD. Endodontic treatment of teeth associated with a large periapical lesion. Int Endod J 2002; 35:73-8. Crosset

18. Saatchi M. Healing of large periapical lesion: a nonsurgical endodontic treatment approach. Aust Endod J 2007;33:136-40. Crossree 